\title{
Occlusion of Sulfate-based Diblock Copolymer Nanoparticles within Calcite: Effect of Varying the Surface Density of Anionic Stabilizer Chains
}

Yin Ning, ${ }^{\dagger}$ Lee A. Fielding,${ }^{\dagger}$ Liam P. D. Ratcliffe,${ }^{\dagger}$ Yun-Wei Wang,${ }^{\S}$ Fiona C. Meldrum, ${ }^{\S}$ Steven P. Armes* ${ }^{*} \dagger$

${ }^{\dagger}$ Department of Chemistry, University of Sheffield, Brook Hill, Sheffield, South Yorkshire S3 7HF, U.K.

The School of Materials, University of Manchester, Oxford Road, Manchester, M13 9PL, U.K.

${ }^{\S}$ School of Chemistry, University of Leeds, Leeds LS2 9JT, U.K.

*s.p.armes@sheffield.ac.uk

\section{Experimental Section}

\subsection{Materials}

Ammonium 2-sulfatoethyl methacrylate (Bisomer SEM® solution, supplied as a $25.0 \% \mathrm{w} / \mathrm{v}$ aqueous solution) and glycerol monomethacrylate (GMA; 99.8\%) were supplied by GEO Specialty Chemicals (Hythe, UK) and used without further purification. Benzyl methacrylate (BzMA) was purchased from Alfa Aesar (UK) and passed through a basic aluminum oxide column to remove inhibitor prior to use. 4,4'-Azobis(4-cyanovaleric acid) (ACVA; 99\%), 4cyano-4-(phenylcarbonothioylthio)pentanoic acid (CPCP), ammonium carbonate and calcium chloride hexahydrate were all purchased from Sigma-Aldrich (UK) and used as received. Deionized water was obtained from an in-house Elgastat Option 3A water purification unit. All solvents were obtained from Sigma-Aldrich (UK). 


\subsection{Synthesis of PSEMx $\left(S_{x}\right)$ macro-CTA}

The synthesis of this macro-CTA has been described elsewhere. $\left.{ }^{[6]}\right]$ Briefly, a typical protocol for the synthesis of $\operatorname{PSEM}_{73}$ macro-CTA is as follows: a $25 \% \mathrm{w} / \mathrm{v}$ aqueous solution of SEM monomer $(136.0 \mathrm{~g}, 0.15 \mathrm{~mol}$; target $\mathrm{DP}=60)$ was weighed into a $250 \mathrm{~mL}$ round-bottomed flask equipped with a magnetic stirrer. Before addition of the CPCP RAFT agent $(0.70 \mathrm{~g}$, $2.50 \mathrm{mmol})$ and ACVA initiator $(0.14 \mathrm{~g}, 0.50 \mathrm{mmol}$; CPCP/ACVA molar ratio $=5.0)$, the solution $\mathrm{pH}$ was adjusted to $\mathrm{pH} 6$ by dropwise addition of $1 \mathrm{M} \mathrm{NaOH}$ solution. The flask was sealed using a rubber septum and degassed with $\mathrm{N}_{2}$ for 30 min and then transferred to an oil bath preheated to $70{ }^{\circ} \mathrm{C}$. After $2 \mathrm{~h}$, the RAFT polymerization was quenched by cooling the flask in ice followed by exposure to air. The reaction mixture was then placed in a $-20{ }^{\circ} \mathrm{C}$ freezer overnight. The remaining polymer was dissolved in methanol and filtered to remove any excess insoluble monomer; thereafter, the filtrate was added dropwise to excess dichloromethane with continuous stirring to precipitate the polymer. The solvent was carefully decanted, the precipitate was redissolved in water and freeze-dried overnight to obtain the PSEM Pacro-CTA. $^{1} \mathrm{H}$ NMR studies indicated $90 \%$ conversion and the CTA efficiency was calculated to be 74\%. Aqueous GPC analysis (vs. poly(ethylene oxide) standards) indicated $M_{\mathrm{n}}$ and $M_{\mathrm{w}} / M_{\mathrm{n}}$ values of $14,900 \mathrm{~g} \mathrm{~mol}^{-1}$ and 1.12 , respectively.

\subsection{Synthesis of PSEM $x-P B z M A_{y}\left(S_{x}-B_{y}\right)$ diblock copolymer nanoparticles}

The synthesis of $\mathrm{PSEM}_{73}-\mathrm{PBzMA}_{300}$ at $10 \% \mathrm{w} / \mathrm{w}$ solids is representative and was conducted as follows. PSEM 73 macro-CTA $(337 \mathrm{mg}, 20.0 \mu \mathrm{mol})$ and ACVA initiator (1.9 mg; $6.7 \mu \mathrm{mol}$, macro-CTA/ACVA molar ratio = 3.0) were weighed into a vial containing a magnetic stirrer bar. BzMA (1057 mg, $6.0 \mathrm{mmol}$, target DP = 300) was added, followed by $12.5 \mathrm{~g}$ of either deionized water for aqueous emulsion polymerization or a $2: 1 \mathrm{v} / \mathrm{v}$ ethanol/water mixture for dispersion polymerization. The vial was sealed and purged with $\mathrm{N}_{2}$ for 30 min prior to transfer to a preheated oil bath set at $70{ }^{\circ} \mathrm{C}$ for $24 \mathrm{~h}$. For diblock copolymer nanoparticles 
prepared by RAFT dispersion polymerization, the ethanol co-solvent was removed by dialysis against deionized water (dialysis tubing $\mathrm{MWCO}=5,000$ ).

\subsection{Synthesis of PGMA $A_{70}\left(G_{70}\right)$ macro-CTA via $R A F T$ solution polymerization}

A typical protocol for the synthesis of PGMA $_{70}$ macro-CTA is as follows. To a roundbottomed flask containing CPCP RAFT agent (0.96 g, 3.43 mmol), GMA monomer (38.44 g, $0.24 \mathrm{~mol})$ and anhydrous ethanol $(59.40 \mathrm{~g}, 1.28 \mathrm{~mol})$ were added to afford a target degree of polymerization (DP) of 70 . To this mixture, ACVA initiator $(0.19 \mathrm{~g}, 0.69 \mathrm{mmol}, \mathrm{CTA} / \mathrm{ACVA}$ molar ratio $=5.0$ ) was added and the resulting pink solution was sparged with $\mathrm{N}_{2}$ for 20 min, before the sealed flask was immersed into an oil bath set at $70{ }^{\circ} \mathrm{C}$. After $2.5 \mathrm{~h}(88 \%$ conversion as judged by ${ }^{1} \mathrm{H}$ NMR) the polymerization was quenched by immersing the reaction flask in an ice bath and exposing its contents to air. The polymer solution was then precipitated into a ten-fold excess of dichloromethane and washed three times in this solvent before being placed under high vacuum for three days at $40{ }^{\circ} \mathrm{C} .{ }^{1} \mathrm{H}$ NMR analysis indicated a DP of 70 for this PGMA macro-CTA. Taking into account the target DP of 70 and the conversion of $88 \%$, this suggests a CTA efficiency of $88 \%$. DMF GPC analysis (vs. poly(methyl methacrylate) standards) indicated $M_{\mathrm{n}}$ and $M_{\mathrm{w}} / M_{\mathrm{n}}$ values of $16,500 \mathrm{~g} \mathrm{~mol}^{-1}$ and 1.11 , respectively.

\subsection{Synthesis of PGMA $A_{70}-P B z M A_{300}$ diblock copolymer nanoparticles}

$\mathrm{G}_{70}$ macro-CTA $(115 \mathrm{mg}, 10 \mu \mathrm{mol})$ and ACVA initiator $(0.9 \mathrm{mg} ; 3.3 \mu \mathrm{mol}$, macroCTA/ACVA molar ratio $=3.0$ ) were weighed into a $17 \mathrm{~mL}$ vial containing a magnetic stirrer bar. Thereafter, deionized water $(6.0 \mathrm{~g})$ and BzMA $(529 \mathrm{mg}, 3 \mathrm{mmol}$, target DP $=300)$ were added, giving a final solids concentration of $10 \mathrm{wt} \%$. The vial was sealed and purged with $\mathrm{N}_{2}$ for $30 \mathrm{~min}$ prior to transfer to a preheated oil bath set at $70{ }^{\circ} \mathrm{C}$ for $24 \mathrm{~h}$. 


\subsection{Synthesis of $\left[0.5 S_{73}+0.5 G_{70}\right]-B_{300}$ diblock copolymer nanoparticles}

$\mathrm{S}_{73}$ macro-CTA $(84 \mathrm{mg}, 5 \mu \mathrm{mol}), \mathrm{G}_{70}$ macro-CTA $(57 \mathrm{mg}, 5 \mu \mathrm{mol})$ and ACVA initiator $(0.9$ $\mathrm{mg} ; 3.3 \mu \mathrm{mol}$, total macro-CTA/ACVA molar ratio $=3.0)$ were weighed into a vial containing a magnetic stirrer bar. Thereafter, deionized water and BzMA (529 mg, 3 mmol, target $\mathrm{DP}=300$ ) were added, targeting a final copolymer concentration of $10 \% \mathrm{w} / \mathrm{w}$ solids. The vial was sealed and purged with $\mathrm{N}_{2}$ for 30 min prior to transfer to a preheated oil bath set at $70{ }^{\circ} \mathrm{C}$ for $24 \mathrm{~h}$.

\subsection{Precipitation of calcium carbonate crystals in the presence of nanoparticles}

$\mathrm{CaCO}_{3}$ crystals were precipitated onto a glass slide placed at the base of an aqueous solution containing $1.5 \mathrm{mM} \mathrm{CaCl} 2$ and various diblock copolymer nanoparticles ranging in concentration from $0.001 \% \mathrm{w} / \mathrm{w}$ to $0.1 \% \mathrm{w} / \mathrm{w}$ by exposure to ammonium carbonate vapor for $24 \mathrm{~h}$ at $20{ }^{\circ} \mathrm{C}$. Then the glass slide was removed from the solution and washed three times with deionized water followed by three rinses with ethanol. Each occlusion experiment was repeated at least twice and consistent results were obtained in each case.

\subsection{Precipitation of zinc oxide crystals in the presence of nanoparticles}

Aqueous copolymer nanoparticle dispersions $(0.20 \mathrm{~mL}, 5.0 \% \mathrm{w} / \mathrm{w})$ were added to a twonecked flask containing an aqueous solution of zinc nitrate hexahydrate $(0.446 \mathrm{~g}, 1.50 \mathrm{mmol})$ to give a total volume of $98.0 \mathrm{~mL}$. This flask was connected to a condenser and transferred to a preheated oil bath set at $90{ }^{\circ} \mathrm{C}$ and the reaction mixture was magnetically stirred to achieve thermal equilibrium (typically $30 \mathrm{~min}$ ). $\mathrm{ZnO}$ formation occurred on addition of $2.0 \mathrm{~mL}$ of an aqueous solution of HMTA $(0.210 \mathrm{~g}, 1.50 \mathrm{mmol})$. The reaction was quenched after $90 \mathrm{~min}$ by cooling in an ice-water bath. The resulting nanocomposite crystals were isolated by centrifugation and washed several times using water or ethanol, followed by drying under vacuum at $40{ }^{\circ} \mathrm{C}$. 


\section{Characterization}

\section{1. ${ }^{1} \mathrm{H}$ NMR spectroscopy}

${ }^{1} \mathrm{H}$ NMR spectra were recorded using a Bruker Avance 400 spectrometer operating at 400 MHz using $\mathrm{D}_{2} \mathrm{O}, \mathrm{CD}_{3} \mathrm{OD}$ or $\mathrm{d}_{6}$-DMSO as solvents.

\subsection{Gel permeation chromatography (GPC)}

Aqueous GPC analysis was performed using an Agilent Technologies Infinity 1260 set-up equipped with two PL aquagel-OH $308 \mu \mathrm{m}$ columns running at $35{ }^{\circ} \mathrm{C}$. The GPC eluent comprised deionized water containing 30 vol \% methanol at $\mathrm{pH} 9$ at a flow rate of $1.0 \mathrm{~mL}$ $\min ^{-1}$. Calibration was achieved using a series of near-monodisperse poly(ethylene oxide) standards ranging from $4.1 \times 10^{3}$ to $6.92 \times 10^{5} \mathrm{~g} \mathrm{~mol}^{-1}$. The DMF GPC set-up was operated at $60{ }^{\circ} \mathrm{C}$ with the instrument comprising two Polymer Laboratories PL gel $5 \mu \mathrm{m}$ Mixed $\mathrm{C}$ columns and one PL polar gel $5 \mu \mathrm{m}$ guard column connected in series to a Varian 390-LC multi-detector suite (refractive index detector only) and a Varian 290-LC pump injection module. The GPC eluent was HPLC-grade DMF containing $10 \mathrm{mM} \mathrm{LiBr}$ and was filtered prior to use. The flow rate was $1.0 \mathrm{~mL} \mathrm{~min}^{-1}$ and DMSO was used as a flow-rate marker. Calibration was conducted using a series of ten near-monodisperse poly(methyl methacrylate) standards $\left(M_{\mathrm{n}}=6.25 \times 10^{2}-6.18 \times 10^{5} \mathrm{~g} \mathrm{~mol}^{-1}, K=2.094 \times 10^{-3}, \alpha=0.642\right)$. Chromatograms were analyzed using Varian Cirrus GPC software.

\subsection{Dynamic light scattering (DLS)}

DLS measurements were conducted using a Malvern Zetasizer NanoZS instrument by detecting back-scattered light at an angle of $173^{\circ}$. Aqueous dispersions of the copolymer nanoparticles were diluted to $0.15 \%$ w/v using deionized water. Aqueous electrophoresis measurements were conducted using disposable folded capillary cells supplied by Malvern (DTS1070) using the same instrument using $1 \mathrm{mM} \mathrm{NaCl}$ as a background electrolyte. For zeta potential vs. $\mathrm{Ca}^{2+}$ concentration studies, the concentration of diblock copolymer 
nanoparticle was fixed at $0.01 \% \mathrm{w} / \mathrm{w}$. Each measurement was repeated three times and averaged to give the mean zeta potential.

\subsection{Transmission electron microscopy (TEM)}

TEM images were obtained by depositing $0.15 \% \mathrm{w} / \mathrm{v}$ aqueous dispersion of copolymer nanoparticles onto palladium-copper grids (Agar Scientific, UK) coated with carbon film. The grids were treated with a plasma glow discharge for approximately 30 seconds to create a hydrophilic surface prior to addition of the aqueous nanoparticle dispersion ( $5 \mu \mathrm{L})$. Excess solvent was removed via blotting and the grid was stained with uranyl formate for 30 seconds. Excess stain was removed via blotting and the grid was carefully dried under vacuum. Imaging was performed using a FEI Tecnai G2 Spirit instrument.

\subsection{Field emission-scanning electron microscopy (FE-SEM)}

Calcite crystal morphologies were examined using a high-resolution field emission-scanning electron microscope (Nova NanoSEM 450). Glass slides supporting the $\mathrm{CaCO}_{3}$ crystals were mounted on stubs using adhesive conductive pads with no further coating. Samples were fractured by placing a clean glass slide on top of the glass slide supporting the calcite crystals, pressing down lightly and twisting one slide relative to the other. A relatively low accelerating voltage $(2-3 \mathrm{kV})$ was applied in order to prevent sample charging.

\section{6. $X$-ray photoelectron spectroscopy (XPS)}

XPS samples were prepared by placing a droplet of an aqueous dispersion of diblock copolymer nanoparticles onto clean indium foil and allowing evaporation to occur overnight at $20{ }^{\circ} \mathrm{C}$. Powder samples were directly pressed onto clean indium foil. XPS data were acquired using a Kratos Axis Ultra DLD instrument equipped with monochromatic Al X-ray

radiation at $6.0 \mathrm{~mA}$ and $15 \mathrm{kV}$ at a typical base pressure of $10^{-8}$ Torr. The step size was 0.5 $\mathrm{eV}$ for the survey spectra (pass energy $=160 \mathrm{eV}$ ) and $0.05 \mathrm{eV}$ for the high resolution spectra (pass energy $=20 \mathrm{eV}$ ). Raw data were corrected using a transmission function characteristic 
of the instrument, determined using software provided by the National Physical Laboratory. The calibrated spectra can then be quantified using theoretically-derived Scofield relative sensitivity factors.

\subsection{Other measurements}

Optical microscopy images were recorded using a Motic DMBA300 digital biological microscope equipped with a built-in camera and analyzed using Motic Images Plus 2.0 ML software. Raman spectra were recorded using a Renishaw 2000 Raman microscope equipped with a $785 \mathrm{~nm}$ diode laser. Thermogravimetric analysis (TGA) was conducted using a PerkinElmer Pyris 1 TGA instrument from $20{ }^{\circ} \mathrm{C}$ to $1000{ }^{\circ} \mathrm{C}$ under air at a heating rate of $15{ }^{\circ} \mathrm{C}$ per min. The amount of calcium chelated by the diblock copolymer was measured using a calcium-selective electrode (Ion selective combination electrode Eutech Calcium, Fisher Scientific). The calcium-selective electrode was then immersed into the polymer solutions to measure the free $\mathrm{Ca}^{2+}$ concentration. A calibration curve was produced prior to the measurement using a range of $\mathrm{CaCl}_{2}$ standard solutions $(0.0001,0.001,0.01$, and 0.1$)$. The samples were then quantified by means of the calibration curve $\left(y=25.41 x+452.3, R^{2}>\right.$ 0.999, see Figure S13). The amount of polymer-bound calcium was calculated from the total amount of $\mathrm{Ca}^{2+}$ added and the amount of free $\mathrm{Ca}^{2+}$ measured. FT-IR spectra were recorded on KBr pellets using a Nicolet 7199 FT-IR spectrometer. UV-visible spectra were recorded at $20{ }^{\circ} \mathrm{C}$ using a PerkinElmer Lambda 25 instrument operating between 200 and $800 \mathrm{~nm}$.

\section{Extent of occlusion determined by thermogravimetric analysis}

Heating calcite control led to decomposition above $625{ }^{\circ} \mathrm{C}$ leaving a final oxide residue of $56.4 \% \mathrm{w} / \mathrm{w}$, which is slight higher than theoretical value $(56.0 \% \mathrm{w} / \mathrm{w})$, most probably due to instrumental error. TGA studies indicated that PSEM $_{73}-\mathrm{PBzMA}_{300}$ (emulsion)/calcite nanocomposite crystal exhibited a $3.7 \%$ weight loss between $250{ }^{\circ} \mathrm{C}$ and $600{ }^{\circ} \mathrm{C}$. This is due to pyrolysis of copolymer nanoparticles located on or near the outer surfaces of the crystals. 
The additional $44.1 \%$ weight loss observed between $600{ }^{\circ} \mathrm{C}$ and $850{ }^{\circ} \mathrm{C}$ is due to both copolymer pyrolysis and $\mathrm{CO}_{2}$ evolution from the thermal decomposition of $\mathrm{CaCO}_{3}$. As the $\mathrm{PSEM}_{73}-\mathrm{PBzMA}_{300}$ copolymer nanoparticles were fully pyrolysed, all of the $52.2 \% \mathrm{w} / \mathrm{w}$ residue is $\mathrm{CaO}$ derived from the decomposition of $\mathrm{CaCO}_{3}$, corresponding to $40.3 \% \mathrm{w} / \mathrm{w} \mathrm{CO}_{2}$. Thus the copolymer nanoparticle content of the original nanocomposite crystals can be calculated to be $7.5 \% \mathrm{w} / \mathrm{w}$ [extent of occlusion $=3.7 \% \mathrm{w} / \mathrm{w}+(44.1 \% \mathrm{w} / \mathrm{w}-40.3 \% \mathrm{w} / \mathrm{w})$ ] The density of dry PSEM$_{73}-\mathrm{PBzMA}_{300}$ (emulsion) nanoparticles is $1.18 \mathrm{~g} \mathrm{~cm}^{-3}$, as determined by helium pycnometry (Micrometrics AccuPyc 1330 helium pycnometer at $20^{\circ} \mathrm{C}$ ). Thus the volume percentage of occluded copolymer nanoparticles within calcite crystal is around $16 \%$ $\mathrm{v} / \mathrm{v}$. 


\section{Theoretical calculations}

\section{Stabilizer surface density $\left(D_{S}\right.$, chains $\left./ \mathbf{n m}^{2}\right)$}

Known parameters: Mass of PSEM macro-CTA $\left(m_{S}, \mathrm{~g}\right)$; number of moles of PSEM macroCTA $\left(n_{P S E M}, \mathrm{~mol}\right)$; mass of PBzMA $\left(m_{b}, \mathrm{~g}\right)$; average radius of dry diblock copolymer nanoparticles $(r, \mathrm{~nm})$ can be obtained from TEM images by averaging at least 200 nanoparticles; Density of $\operatorname{PSEM}_{73}-\mathrm{PBzMA}_{300}$ nanoparticles $\left(\rho, \mathrm{g} \mathrm{cm}^{-3}\right)$ was determined by helium pycnometry (Micrometrics AccuPyc 1330 helium pycnometer at $20{ }^{\circ} \mathrm{C}$ ); $N_{A}$ refers to Avogadro's number $\left(\mathrm{mol}^{-1}\right)$.

Given high BzMA conversion in all cases (> $99 \%$, as evidenced by ${ }^{1} \mathrm{H}$ NMR) and a high PSEM macro-CTA blocking efficiency (see Figure S1):

Mass of each nanoparticle $(m): m=\rho V=\frac{4}{3} \pi \rho r^{3}$

The number of nanoparticles $(N): N=\frac{m_{s}+m_{b}}{m}=\frac{3\left(m_{s}+m_{b}\right)}{4 \pi \rho r^{3}}$

Surface area of each particle $\left(S_{A}\right): S_{A}=4 \pi r^{2}$

Total surface area of all particles $\left(S_{T A}\right): S_{T A}=S_{A} \times N=4 \pi r^{2} N=\frac{3\left(m_{s}+m_{b}\right)}{\rho r}$

Thus the stabilizer surface density $\left(D_{S}\right.$, chain per $\left.\mathrm{nm}^{2}\right)$ is given by:

$D_{S}=\frac{n_{P S E M} N_{A}}{S_{T A}}=\frac{n_{P S E M} N_{A} \rho r}{3\left(m_{S}+m_{b}\right)} \times 10^{-21}$ 


\section{Aggregation number $\left(\mathbf{N}_{\text {agg }}\right)$}

Given the high monomer conversions and the insolubity of poly(benzyl methacrylate) in water, determining the mean core diameters of the copolymer nanoparticles by TEM allows estimation of the mean aggregation number $\left(N_{\mathrm{agg}}\right)$ using the following two equations. ${ }^{1-3}$

$$
\begin{gathered}
N_{a g g}=\frac{4}{3} \pi R_{\text {core }}^{3} / V_{P B Z M A} \\
V_{P B Z M A}=\frac{M_{n, P B Z M A}}{N_{A} \rho_{P B Z M A}}
\end{gathered}
$$

$\rho_{P B Z M A}$ was determined to be $1.15 \mathrm{~g} \mathrm{~cm}^{-3}$ by helium pycnometry and $M_{n, P B Z M A}$ corresponds to the number-average molecular weight of the PBzMA block determined by ${ }^{1} \mathrm{H}$ NMR spectroscopy. 
Scheme S1. (a) Synthesis of non-ionic poly(glycerol monomethacrylate) ${ }_{70}$-poly(benzyl methacrylate $)_{300}\left(\right.$ PGMA $_{70}-$ PBzMA $\left._{300}\right)$ and (b) $\left[0.5\right.$ PSEM$_{73}+0.5$ PGMA $\left._{70}\right]-P B z M A_{300}$ diblock copolymer nanoparticles at $10 \%$ w/w solids by chain extension with benzyl methacrylate (BzMA) at $70{ }^{\circ} \mathrm{C}$ for $24 \mathrm{~h}$. Similar PISA formulations involving binary mixtures of stabilizers have been reported recently. ${ }^{4-6}$

(a)<smiles>CC(C)(CCC(=O)O)C(C)(C)SC(=O)c1ccccc1</smiles>

ACVA, $\mathrm{H}_{2} \mathrm{O}, 70^{\circ} \mathrm{C}, 24 \mathrm{~h}$ RAFT emulsion polymerization)

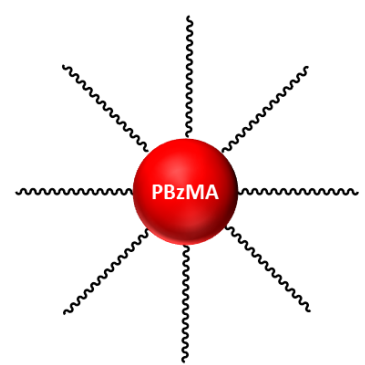

PGMA70-PBzMA 300

(b)

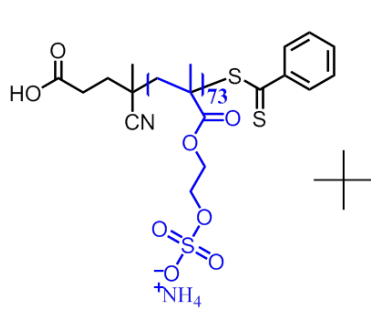<smiles>CC(C)(CCC(=O)O)CC(C)(C)C(=O)OCC(O)CO</smiles>

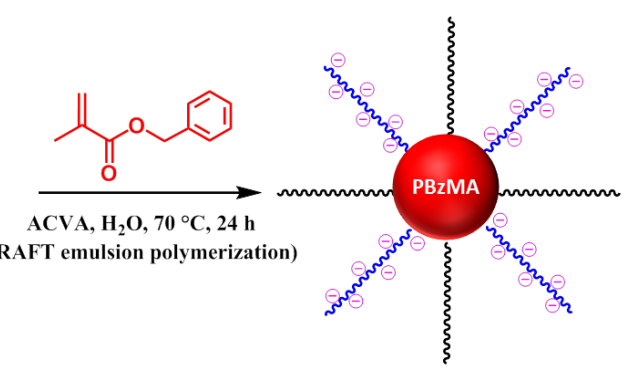

[0.5PSEM73+0.5PGMA70]-PBzMA 300 
Figure S1. Aqueous GPC curves obtained for (a) $\mathrm{PSEM}_{32}$ macro-CTA and (b) $\mathrm{PSEM}_{73}$ macro-CTA and their subsequent chain extension via RAFT aqueous solution polymerization using SEM monomer. This 'self-blocking' experiment was conducted in aqueous solution at $70{ }^{\circ} \mathrm{C}$ using ACVA initiator and a PSEM macro-CTA/ACVA molar ratio of 5.0. Relatively high blocking efficiencies are obtained for these two macro-CTAs, which indicates high RAFT chain-end fidelity. (c) UV-visible spectra obtained for the CPCP chain transfer agent at concentrations ranging from $1.0 \times 10^{-5} \mathrm{M}$ to $1.0 \times 10^{-4} \mathrm{M}$; (d) Beer-Lambert plot for this CPCP RAFT agent recorded in methanol in order to calculate the degree of end-group functionality of each PSEM macro-CTA. The absorbance at a given concentration of PSEMCPCP is divided by the theoretical absorbance calculated from the Beer-Lambert plot $A=\varepsilon c l$ (Figure S1d). For example, the experimental absorbance for $5 \times 10^{-5} \mathrm{M} \mathrm{PSEM}_{73}$ is 0.719, while the theoretical absorbance is 0.724 , thus the RAFT end-group functionality for $\mathrm{PSEM}_{73}$ is given by $(0.719 / 0.724) \times 100 \%$, or $\sim 99.3 \%$.

(a)

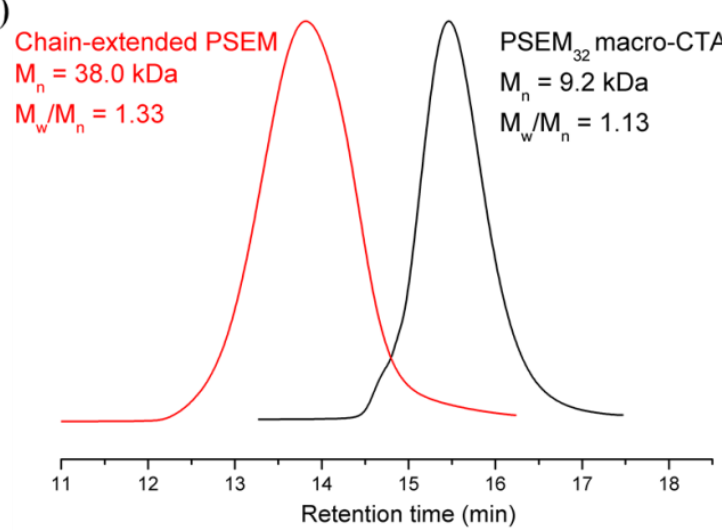

(c)

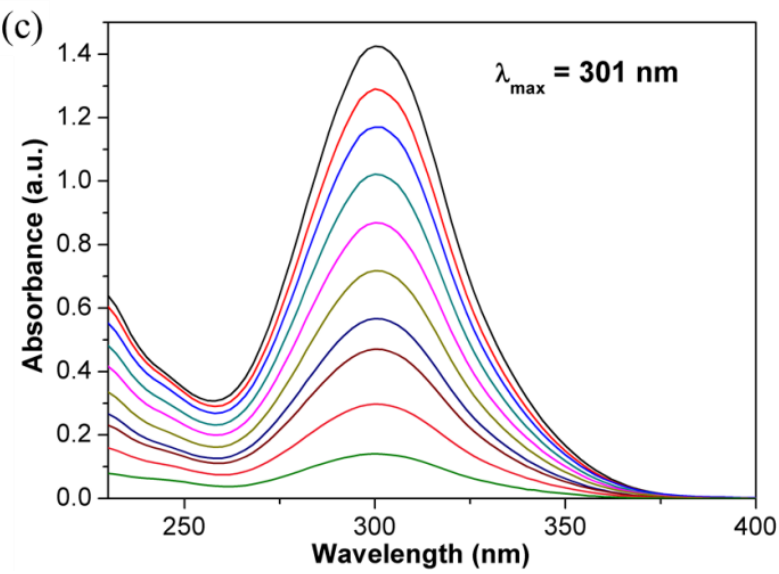

(b)

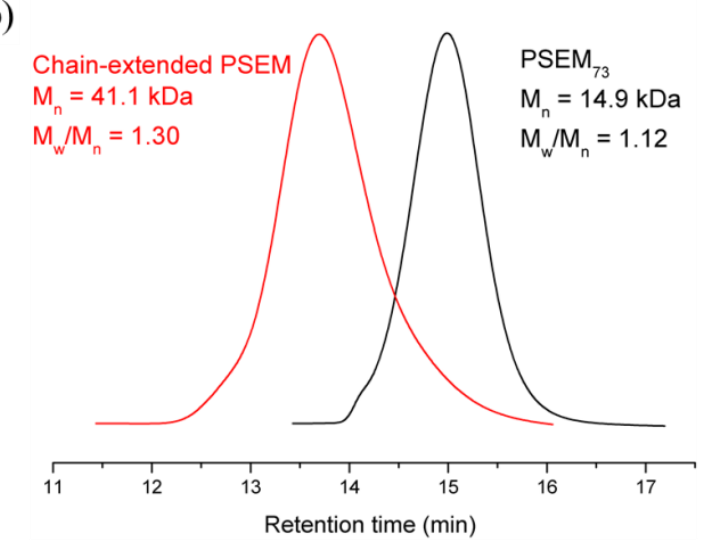

(d)

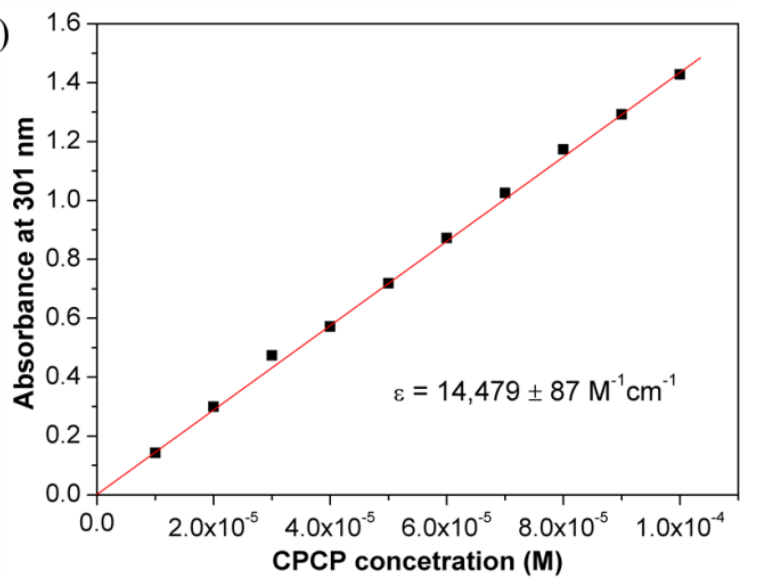


Figure S2. DLS diameters recorded for (a) $\mathrm{S}_{73}-\mathrm{B}_{300}$ (emulsion) and (b) $\mathrm{S}_{73}-\mathrm{B}_{300}$ (dispersion) copolymer nanoparticles in the absence or presence of $1.5 \mathrm{mM} \mathrm{Ca}^{2+}$ ions.
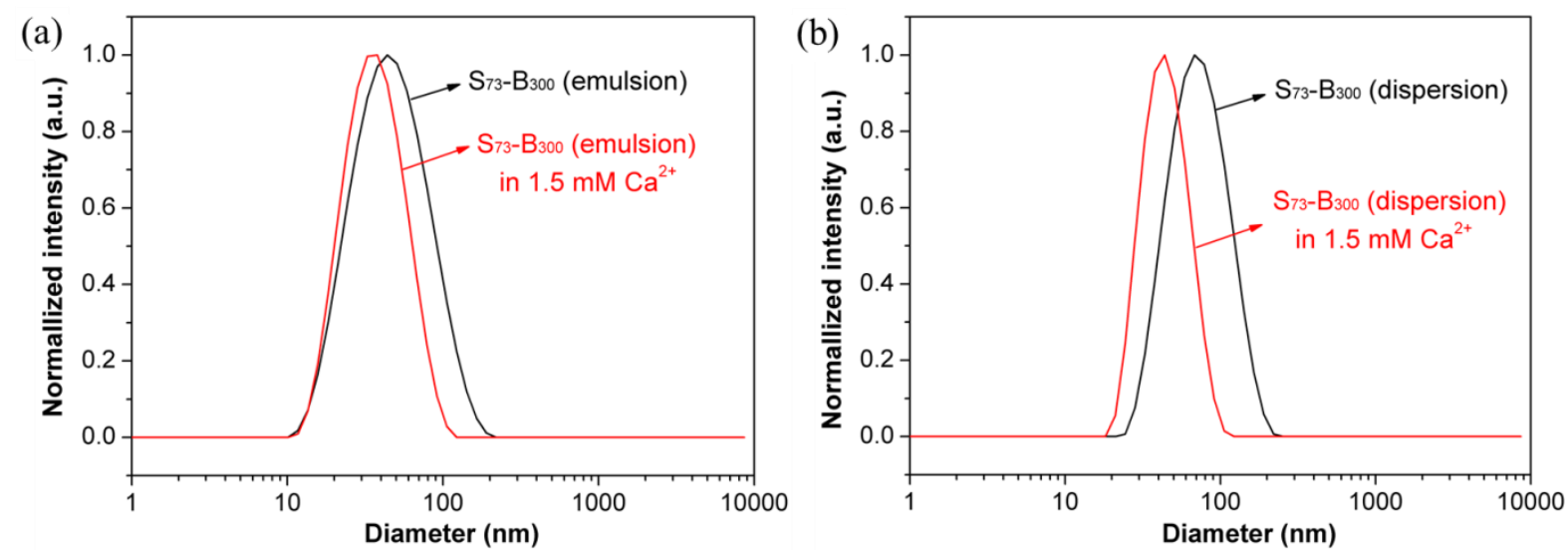

Figure S3. Optical micrograph recorded for calcium carbonate crystals precipitated in the presence of $0.1 \% \mathrm{w} / \mathrm{w} \mathrm{S}_{73}-\mathrm{B}_{300}$ (emulsion) diblock copolymer nanoparticles.

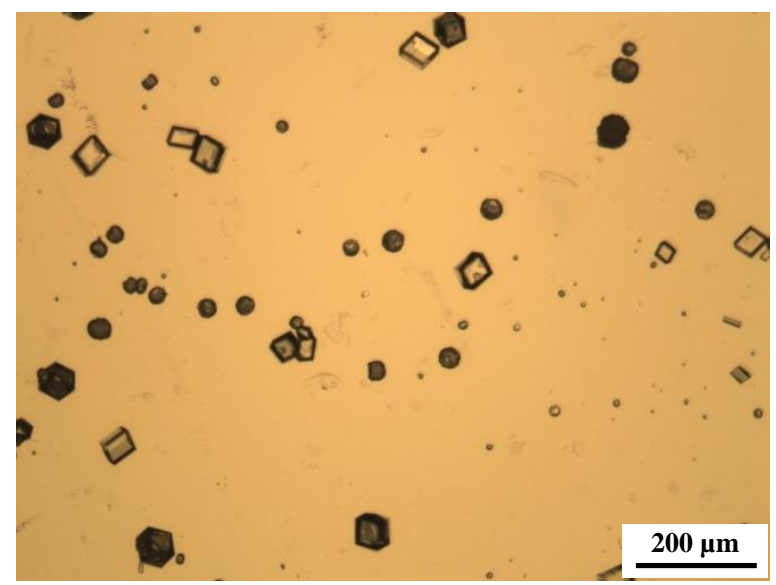


Figure S4. Optical micrographs recorded for calcium carbonate crytsals obtained under various conditions: (a) control calcium carbonate without any additive; (b) calcium carbonate precipitated in the presence of $\operatorname{PSEM}_{73}$ homopolymer (same number of moles as that used for the $\mathrm{S}_{73}-\mathrm{B}_{300}$ diblock copolymer nanoparticle studies); (c) calcium carbonate precipitated in the presence of $0.01 \% \mathrm{w} / \mathrm{w} \mathrm{S}_{73}-\mathrm{B}_{300}$ (emulsion). The insets show the corresponding FE-SEM images.

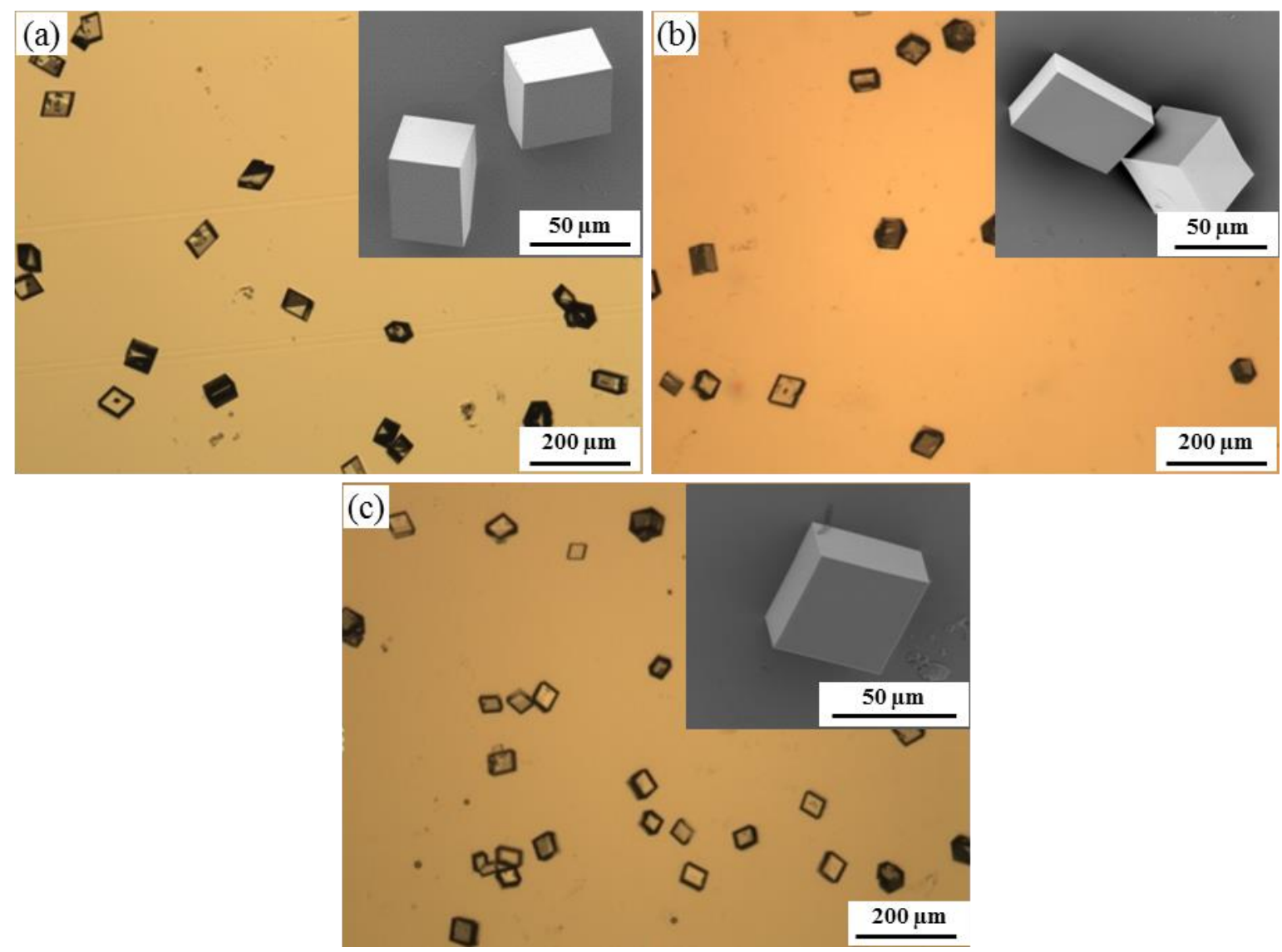


Figure S5. Raman spectra recorded for a calcite control (black spectrum) and a $S_{73}-B_{300}$ (emulsion)/calcite nanocomposite crystal (red spectrum).

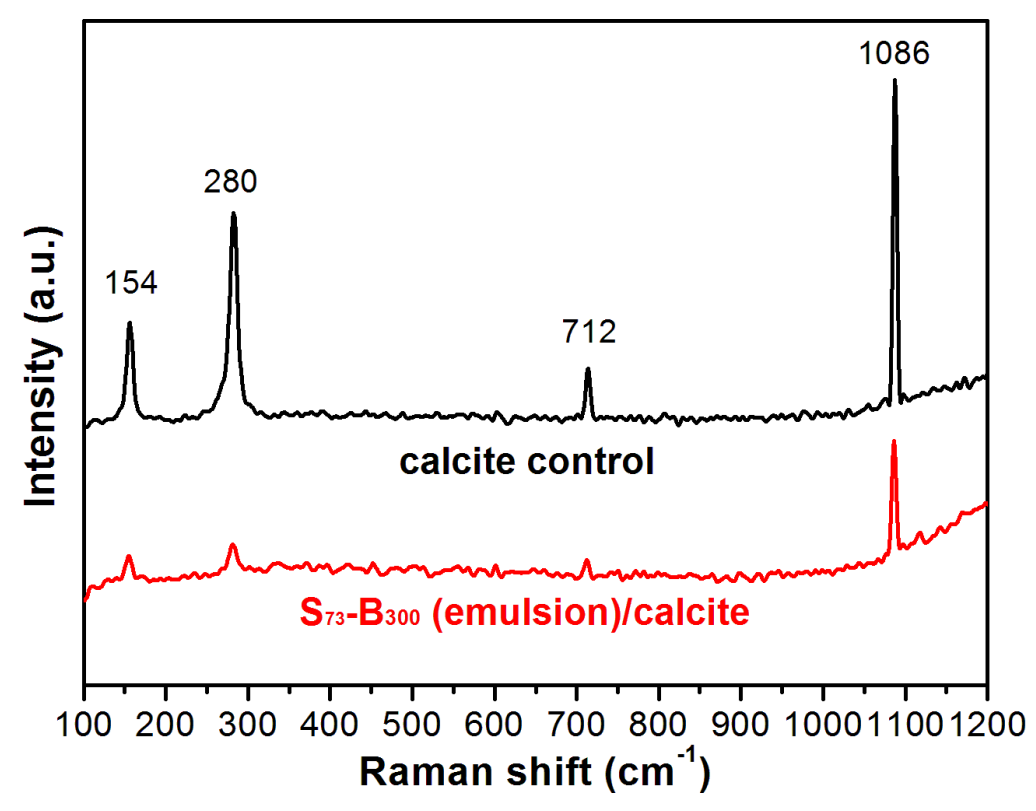

Figure S6. (a) Low magnification FE-SEM images of fractured calcium carbonate crystals precipitated in the presence of $0.01 \% \mathrm{w} / \mathrm{w}$ of $\mathrm{PGMA}_{70}-\mathrm{PBzMA}_{300}$ (emulsion); (b) magnified FE-SEM image showing the rectangular area indicated in (a). The inset in (b) is a TEM image obtained for $\mathrm{PGMA}_{70}-\mathrm{PBzMA}_{300}$ (emulsion). N.B. No occlusion was detected when using PGMA $_{70}-\mathrm{PBzMA}_{100}$ (emulsion) with a smaller particle size (approximate $\left.20 \mathrm{~nm}\right){ }^{7}$ which indicates that the effect of particle size on the extent of occlusion is negligible.
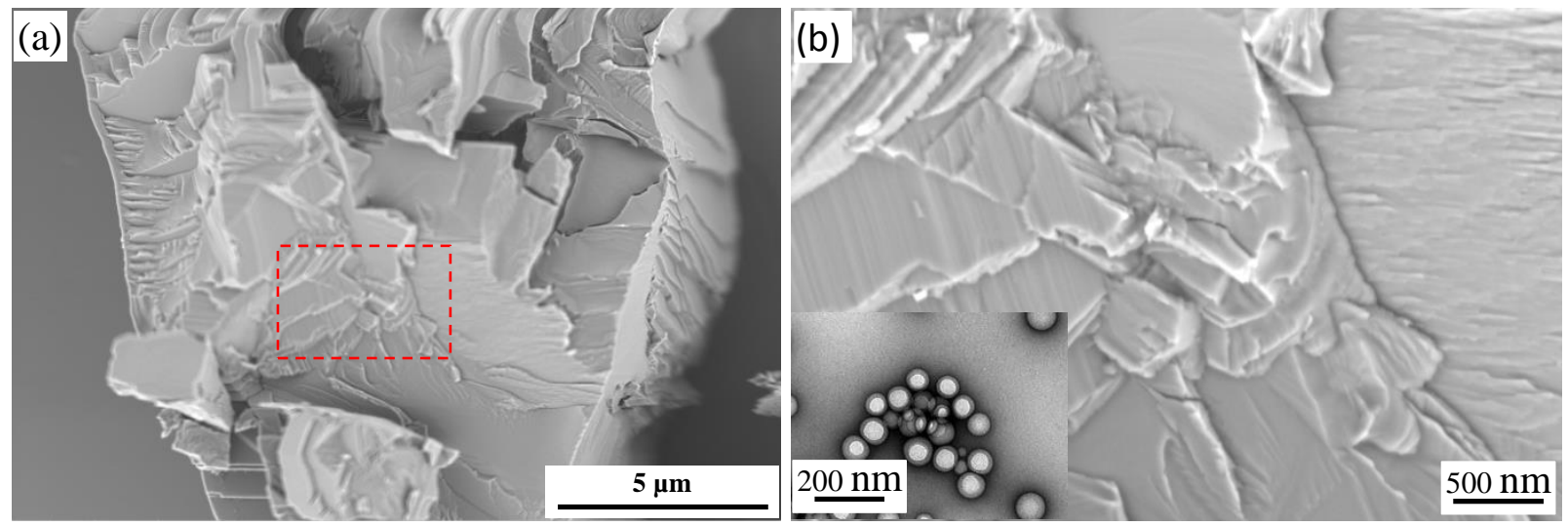
Figure S7. FE-SEM images obtained for fractured calcium carbonate crystals prepared in the presence of $0.01 \% \mathrm{w} / \mathrm{w}\left[0.5 \mathrm{~S}_{73}+0.5 \mathrm{G}_{70}\right]-\mathrm{B}_{300}$ copolymer nanoparticles prepared by RAFT aqueous emulsion polymerization. The inset shows a TEM image of $\left[0.5 \mathrm{~S}_{73}+0.5 \mathrm{G}_{70}\right]-\mathrm{B}_{300}$ diblock copolymer nanoparticles.

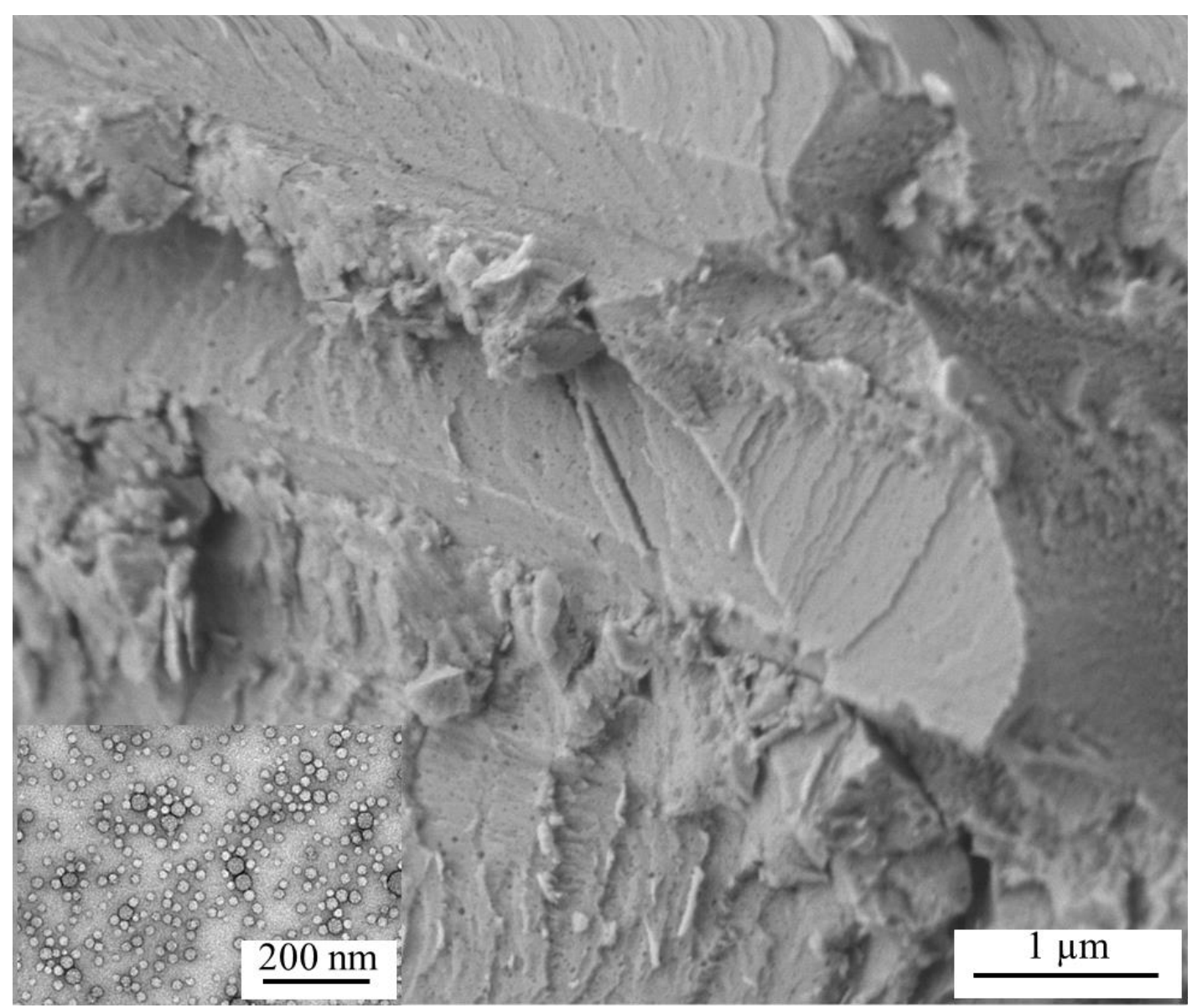


Figure S8. Low magnification FE-SEM images recorded for fractured calcium carbonate cystals precipitated in the presence of $0.01 \% \mathrm{w} / \mathrm{w}$ (a) $\mathrm{S}_{32}-\mathrm{B}_{300}$ (dispersion); (b) $\mathrm{S}_{73}-\mathrm{B}_{300}$ (dispersion); (c) $\mathrm{S}_{32}-\mathrm{B}_{300}$ (emulsion). The red rectangles indicate the areas of the sample that are shown in Figures 3a, 3b and 3c, respectively.
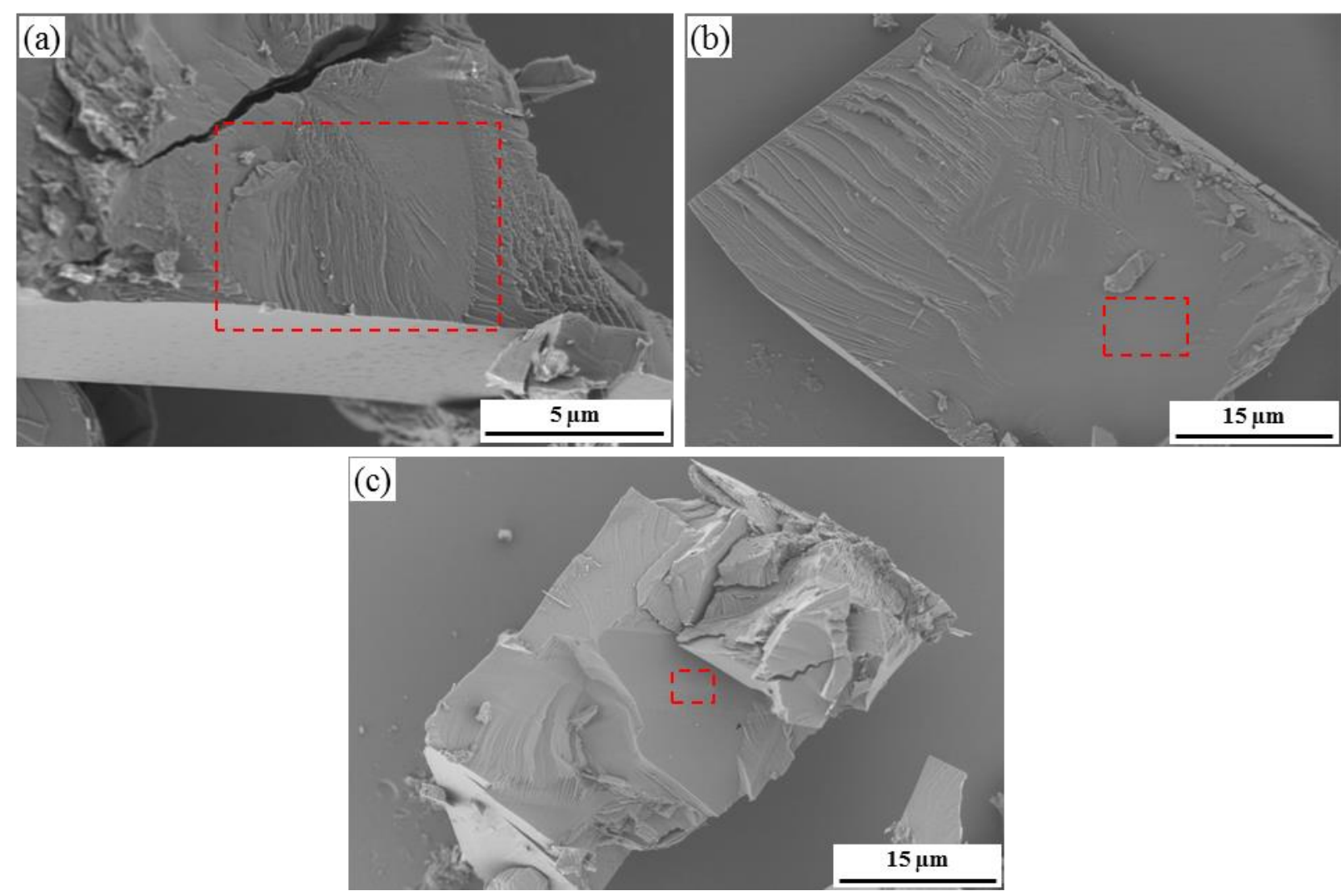
Figure S9. FT-IR spectra recorded for $\mathrm{PSEM}_{73}-\mathrm{PBzMA}_{300}$ (emulsion) nanoparticles alone and nanocomposite crystals comprising PSEM $_{73}-\mathrm{PBzMA}_{300}$ (emulsion) nanoparticles occluded within calcite. A weak ester carbonyl band at $1729 \mathrm{~cm}^{-1}$ is discernible in the latter spectrum, confirming successful occlusion of these copolymer nanoparticles within the calcite crystals. $^{7}$

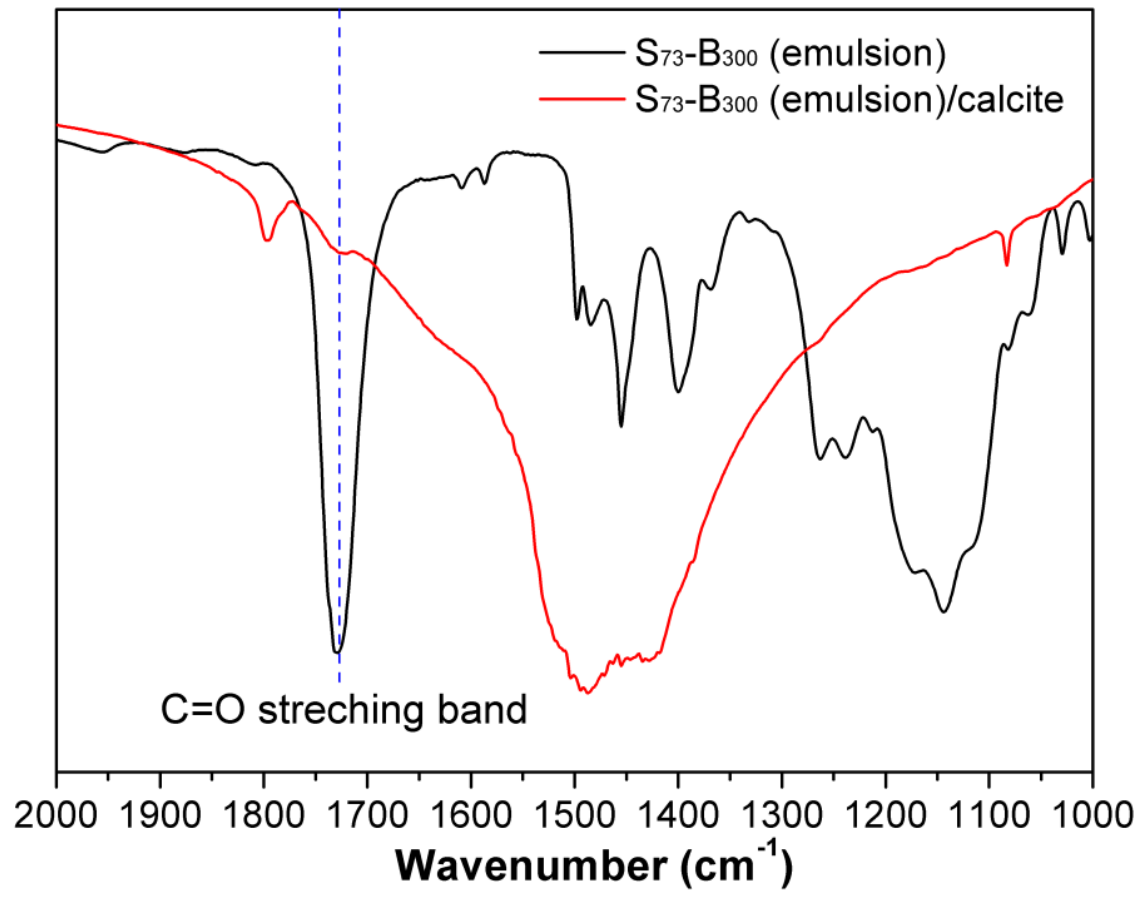


Figure S10. FE-SEM images obtained for fractured calcium carbonate crystals prepared in the presence of $0.01 \% \mathrm{w} / \mathrm{w} \mathrm{S}_{\mathrm{x}}-\mathrm{B}_{\mathrm{y}}$ diblock copolymer nanoparticles prepared by RAFT dispersion polymerization: (a) $\mathrm{S}_{32}-\mathrm{B}_{100}$ (dispersion); (b) $\mathrm{S}_{73}-\mathrm{B}_{100}$ (dispersion); (c) $\mathrm{S}_{32}-\mathrm{B}_{500}$ (dispersion); (d) $\mathrm{S}_{73}-\mathrm{B}_{500}$ (dispersion). Insets show TEM images of the corresponding $\mathrm{S}_{\mathrm{x}}-\mathrm{B}_{\mathrm{y}}$ diblock copolymer nanoparticles prior to occlusion.

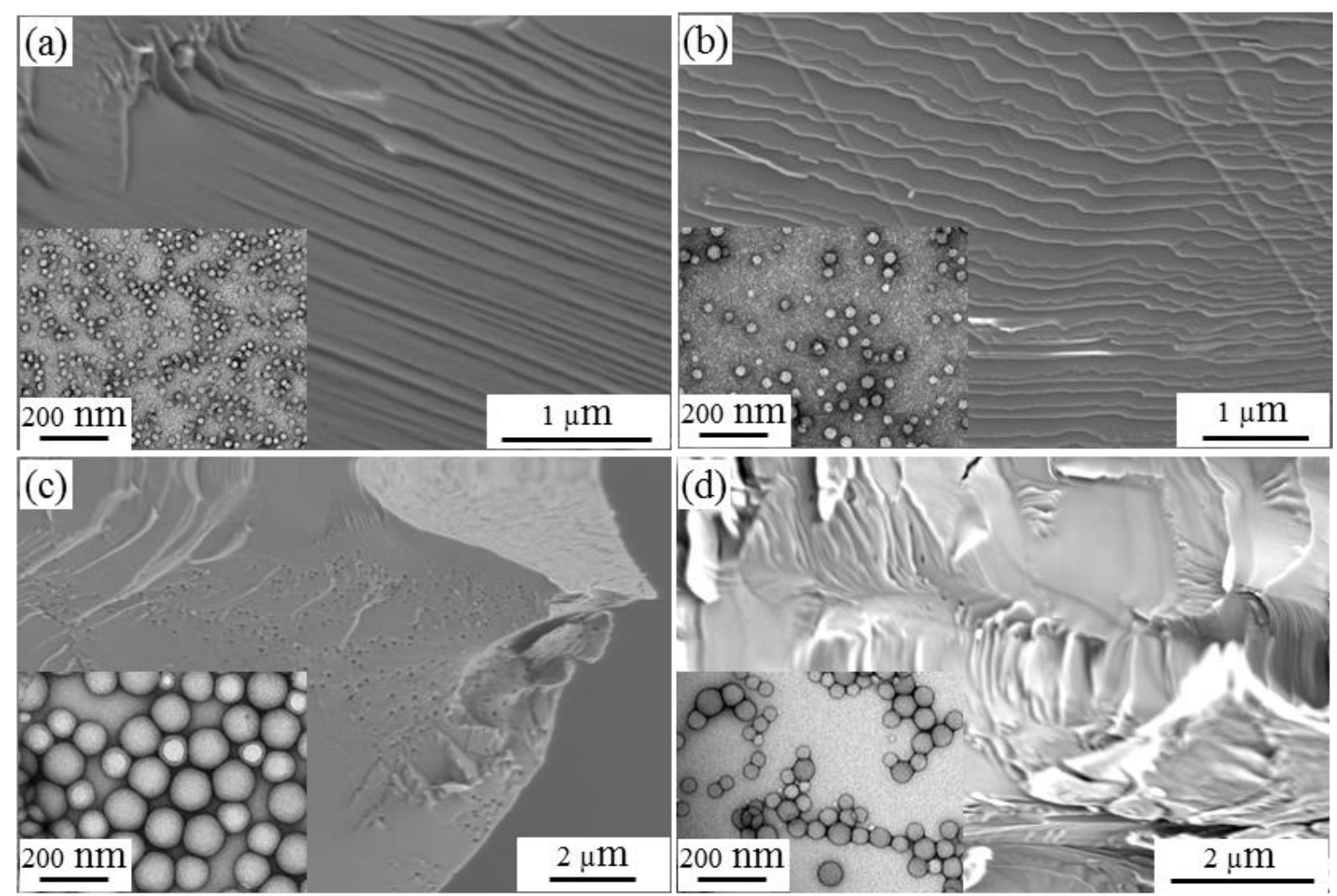


Figure S11. FE-SEM images obtained for fractured calcium carbonate crystals prepared in the presence of $0.01 \% \mathrm{w} / \mathrm{w} \mathrm{S}_{\mathrm{x}}-\mathrm{B}_{\mathrm{y}}$ diblock copolymer nanoparticles prepared by RAFT emulsion polymerization: (a) $\mathrm{S}_{32}-\mathrm{B}_{100}$ (emulsion); (b) $\mathrm{S}_{32}-\mathrm{B}_{500}$ (emulsion); (c) $\mathrm{S}_{73}-\mathrm{B}_{500}$ (emulsion). (d), (e) and (f) show the magnified images as indicated in (c). Insets show TEM images of the corresponding $S_{x}-B_{y}$ diblock copolymer nanoparticles prior to occlusion [N.B. Well-defined $\mathrm{S}_{73}-\mathrm{B}_{100}$ (emulsion) cannot be prepared as the core-forming block is too short].

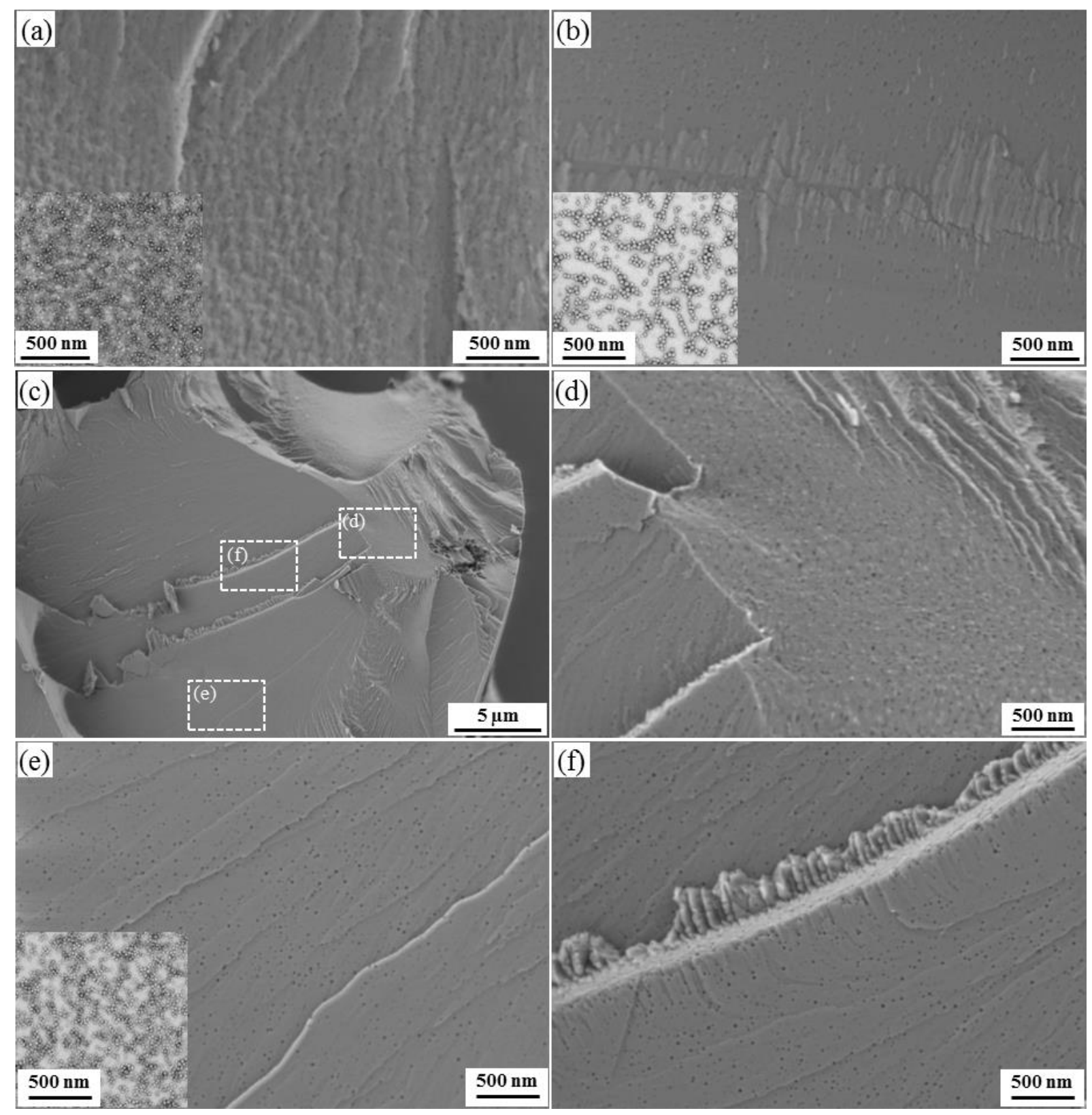


Figure S12. DLS particle size distributions recorded for $\mathrm{PSEM}_{73}-\mathrm{PBzMA}_{300}$ (dispersion) copolymer nanoparticles before and after dialysis against water $(52 \mathrm{~nm}$ before dialysis vs. 60 $\mathrm{nm}$ after dialysis). The slightly higher DLS diameter observed in pure water simply reflects slightly greater stretching of the anionic stabilizer chains. Using SAXS and ${ }^{1} \mathrm{H}$ NMR spectroscopy, we have recently shown that both ethanol and water are non-solvents for the PBzMA core-forming block. ${ }^{8}$ Thus dialysis from 2:1 ethanol/water into pure water is not expected to change the dimensions of these $\mathrm{PSEM}_{73}-\mathrm{PBzMA}_{300}$ nanoparticles.

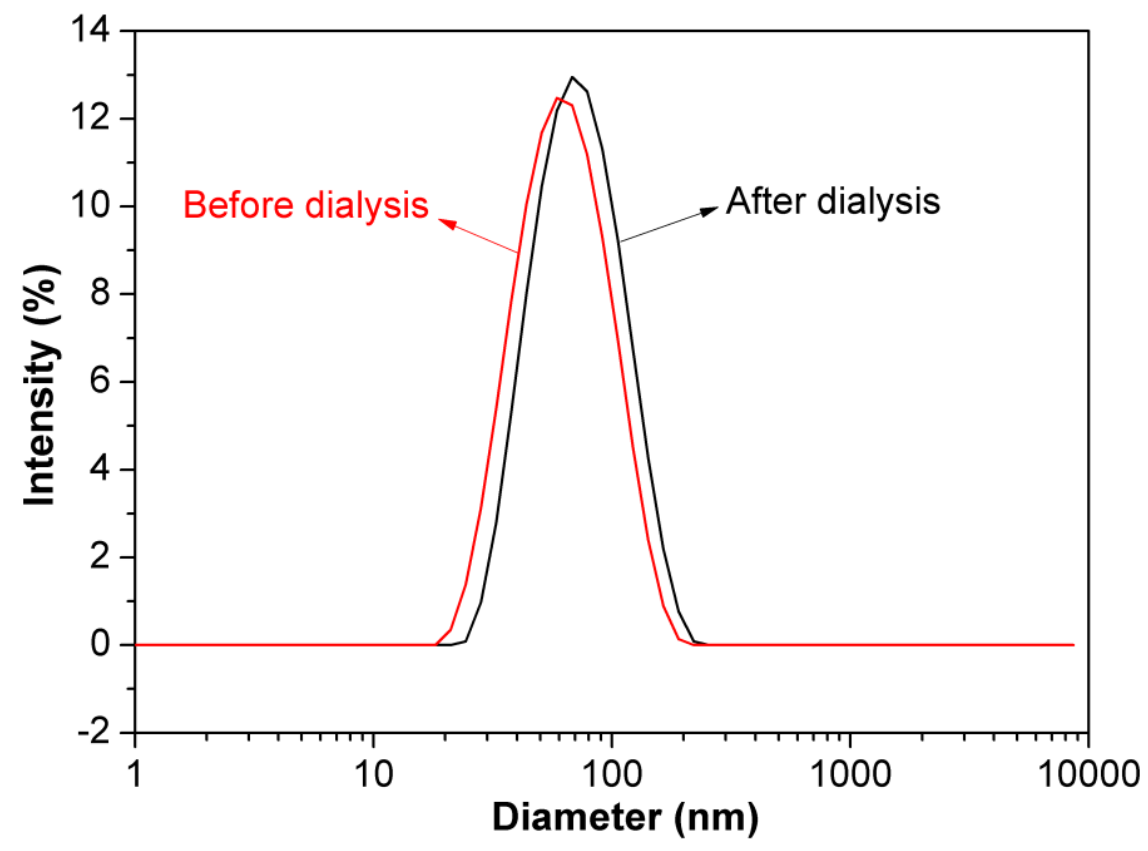


Figure S13. Linear calibration curve $\left(\mathrm{R}^{2}>0.999 ; \mathrm{y}=25.41 \mathrm{x}+452.3\right)$ obtained using a calcium-selective electrode for the determination of calcium complexation by $S_{x}-B_{y}$ diblock copolymer nanoparticles. The amount of copolymer-bound calcium was calculated from the difference between the initial $\mathrm{Ca}^{2+}$ concentration and the concentration of free $\mathrm{Ca}^{2+}$ measured using the ion-selective electrode.

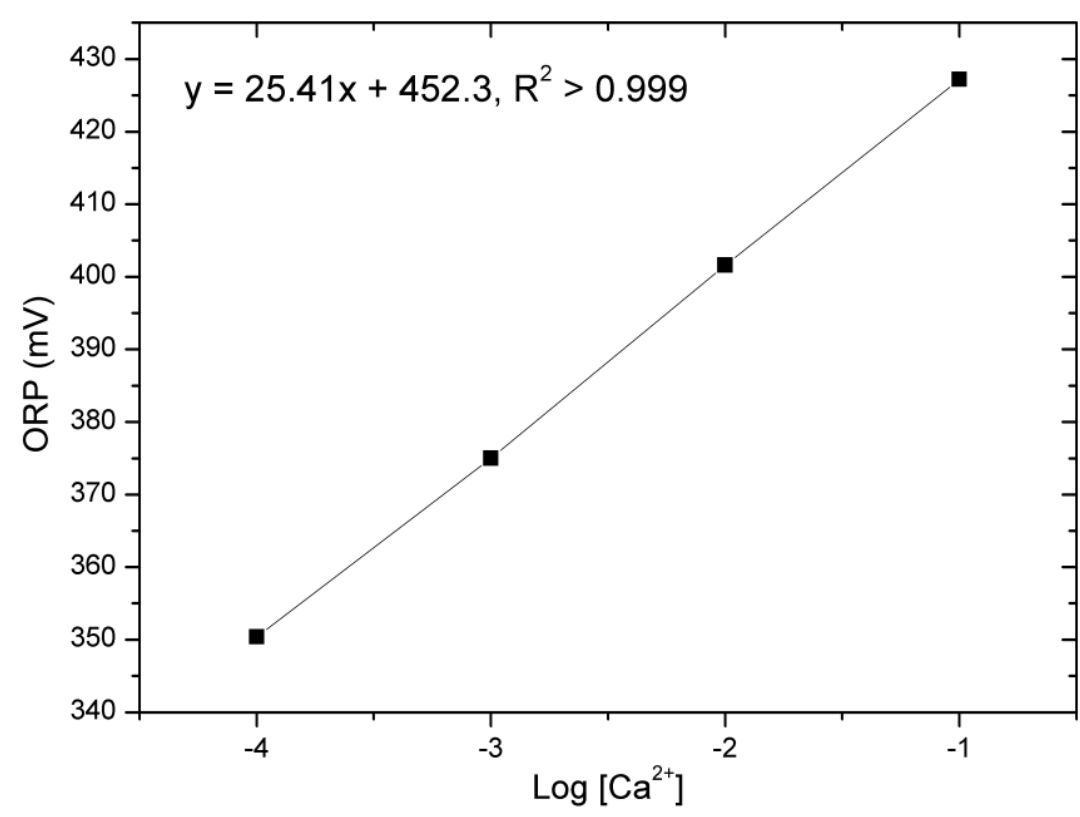


Figure S14. SEM images obtained for $\mathrm{ZnO}$ precipitated in the presence of copolymer nanoparticles. (a) $\mathrm{ZnO}$ control (without any additive); (b) $\mathrm{ZnO}$ precipitated in the presence of $0.01 \% \mathrm{w} / \mathrm{w} \mathrm{S}_{73}-\mathrm{B}_{100}$ (dispersion) copolymer nanoparticles; (c) $\mathrm{ZnO}$ precipitated in the presence of $0.01 \% \mathrm{w} / \mathrm{w} \mathrm{S}_{73}-\mathrm{B}_{300}$ (emulsion) copolymer nanoparticles; (d) TGA curves recorded for these three samples as well as for the $\mathrm{S}_{73}-\mathrm{B}_{300}$ (emulsion) copolymer nanoparticles alone. The insets shown in (b) and (c) are TEM images of the corresponding $\mathrm{S}_{73}-\mathrm{B}_{100}$ (dispersion) and $\mathrm{S}_{73}-\mathrm{B}_{300}$ (emulsion) copolymer nanoparticles. N.B. The former nanoparticles were chosen for the $\mathrm{ZnO}$ occlusion experiments, because their mean diameter is comparable with that of the $\mathrm{S}_{73}-\mathrm{B}_{300}$ (emulsion) copolymer nanoparticles (see Table 1). These copolymer nanoparticle/ZnO nanocomposite crystals were heated up to $900{ }^{\circ} \mathrm{C}$ in air to remove the copolymer component via pyrolysis and then gold-coated prior to SEM imaging.
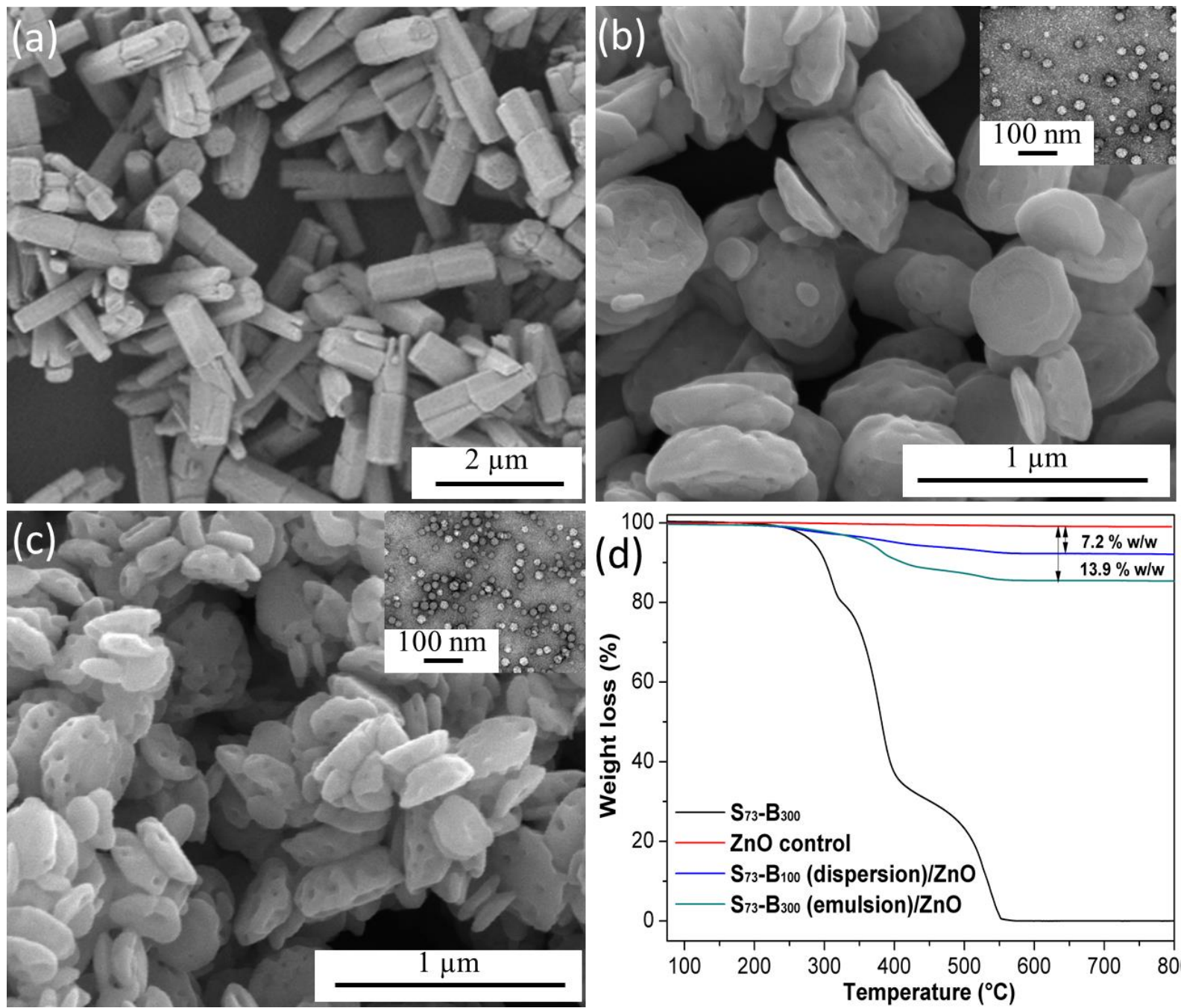


\section{References}

(1) Zhang, L.; Eisenberg, A. J. Am. Chem. Soc. 1996, 118, 3168-3181.

(2) Fielding, L. A.; Lane, J. A.; Derry, M. J.; Mykhaylyk, O. O.; Armes, S. P. J. Am. Chem. Soc. 2014, 136, 5790-5798.

(3) Derry, M. J.; Fielding, L. A.; Warren, N. J.; Mable, C. J.; Smith, A. J.; Mykhaylyk, O. O.; Armes, S. P. Chem. Sci. 2016, 7, 5078-5090.

(4) Semsarilar, M.; Ladmiral, V.; Blanazs, A.; Armes, S. P. Langmuir 2012, 28, 914-922.

(5) Semsarilar, M.; Ladmiral, V.; Blanazs, A.; Armes, S. P. Langmuir 2013, 29, 74167424.

(6) Williams, M.; Penfold, N. J. W.; Lovett, J. R.; Warren, N. J.; Douglas, C. W. I.; Doroshenko, N.; Verstraete, P.; Smets, J.; Armes, S. P. Polym. Chem. 2016, 7, 3864-3873. (7) Ning, Y.; Fielding, L. A.; Doncom, K. E. B.; Penfold, N. J. W.; Kulak, A. N.; Matsuoka, H.; Armes, S. P. ACS Macro Lett. 2016, 5, 311-315.

(8) Jones, E.; Mykhaylyk, O.; Semsarilar, M.; Boerakker, M.; Wyman, P.; Armes, S. Macromolecules 2015, 49, 172-181. 